\section{Commentary: Ross procedure in older patients: Decision based on unconscious bias or on science?}

\author{
Emile Bacha, MD
}

It is rare that one is ever asked to write an editorial on an operation he or she has never done. But here it is; I am writing an editorial on a study examining outcomes of the Ross operation in patients age $>50$ years. Despite being a big proponent of the Ross in my own adult congenital clinical practice, in more than 20 years of congenital cardiac surgery practice, I have never done one in a patient over age 50. Is this an unconscious bias of mine or a decision rooted in science? That is the fundamental question that this study aims to examine.

In this issue of the Journal, Chauvette and colleagues ${ }^{1}$ report a retrospective analysis of prospectively collected data from the Canadian Ross Registry (5 Canadian centers, nearly 500 patients over 8 years, and 7 surgeons). Their essential message is that perioperative and mid-term outcomes are similar in patients age $<50$ years and older patients, as well as, importantly, that the incidence of perioperative complications is low in both groups. They also comment on the excellent long-term hemodynamics as well as undistinguishable survival curves in the Ross recipients compared with the sexand age-matched general population. I will not argue these last 2 points, as I completely agree with them.

However, to accept this message as valid for all centers practicing cardiac surgery and all cardiac surgeons, one first must examine the available evidence regarding simple aortic valve replacement (AVR) with either mechanical or bioprosthetic prostheses in a similar group of patients, as well as data on technical outcomes with the Ross procedure. Regarding simple AVRs, the arguments seemingly favor the Ross. Studies examining long-term survival after prosthetic AVR in patients age $<65$ years have consistently shown excessive mortality versus the matched general population. If you also consider the fact that many prosthetic valves implanted are $\leq 23 \mathrm{~mm}$, the valve-in-valve (ViV) option

\footnotetext{
From the Division of Cardiac, Thoracic, and Vascular Surgery, Congenital Heart Center, NewYork-Presbyterian/Columbia University Irving Medical Center, New York, NY.

Received for publication Nov 3, 2020; revisions received Nov 3, 2020; accepted for publication Nov 4, 2020; available ahead of print Nov 20, 2020.

Address for reprints: Emile Bacha, MD, Morgan Stanley Children's Hospital, 3959 Broadway, New York, NY 10032 (E-mail: eb2709@cumc.columbia.edu). J Thorac Cardiovasc Surg 2022;164:845-6 $0022-5223 / \$ 36.00$

Copyright (c) 2020 by The American Association for Thoracic Surgery https://doi.org/10.1016/j.jtcvs.2020.11.026
}

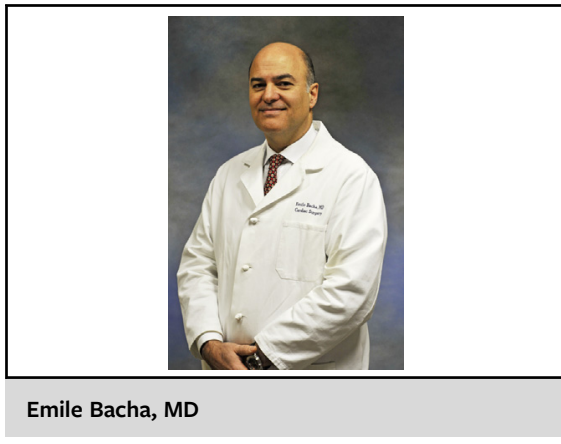

CENTRAL MESSAGE

The Ross procedure can be effective for the right patients. This study shows that the procedure can have good results in patients age $>50$ years; however, this does not imply that it should be done by everyone.

becomes less appealing, particularly if you consider the issues with patient-prosthesis mismatch after ViV. Finally, a transcatheter AVR (TAVR)-first approach is unsuitable in this relatively young and healthy patient population, most of whom were between 50 and 60 years old. Thus, these data argue in favor of a Ross in a healthy 55-year-old, for example. The question then becomes-knowing that the older group had more comorbidities than the younger group-what is required to achieve these enviable outcomes? What is required is technical mastery of this particular operation.

As multiple studies have already demonstrated, outcomes following surgery are largely influenced by a center's experience and a surgeon's volume with that particular operation. The authors make the argument that because they included "the inaugural experience and learning curve" in their study, so-called "non-Ross" centers could join the Ross bandwagon in older patients. They state that "this strongly suggests the operation can be performed safely and reproducibly with adequate proctorship." The last 3 words "with adequate proctorship" are probably the most important 3 words in the entire manuscript. The senior author performed the Ross procedure in 366 of the 497 patients $(73 \%)$. Taking into account the number of cases that he proctored, the study starts to more closely resemble a single-surgeon series than a true multicenter study. In my opinion. this is the study's major weakness, in that it does not demonstrate the generalizability of 
the Ross procedure in the absence of a stand-alone technically proficient and high-volume Ross surgeon.

In summary, this study demonstrates that excellent results can be achieved with the Ross procedure in patients age $>50$ years, provided that the technical expertise is available. However, it does not show (and in all fairness, the authors do not imply) that the Ross procedure should be performed preferentially in these patients.

\section{Reference}

1. Chauvette V, Bouhout I, Tarabzoni M, Wong D, Bozinovski J, Cu MWA, et al. The Ross procedure in patients older than 50: a sensible proposition? J Thorac Cardiovasc Surg. 2022;164:835-44.e5.
See Article page 835 .

\section{Commentary: Out with the new, in with the old: Evaluating the Ross procedure in patients aged $>50$ years}

\section{Ryan P. Plichta, MD, and Edward P. Chen, MD}

The ideal aortic valve replacement option remains elusive. The conventional choice between mechanical prostheses with lifelong anticoagulation therapy or tissue prostheses with the potential need for future reintervention is difficult to make.

The Ross procedure, initially described in 1967, involves translocation of a patient's pulmonary valve to the aortic position and pulmonary homograft replacement of the native pulmonic valve. ${ }^{1}$ Ross procedures currently make up $<1 \%$ of surgical aortic valve replacement procedures in North America. ${ }^{2}$ Reported advantages include excellent hemodynamic parameters and elimination of anticoagulation therapy, as well as outstanding durability and patient survival. Traditionally, it has been performed in young patients with an anticipated life expectancy $>15$ to 20 years.

El-Hamamsy and colleagues ${ }^{3}$ provide a compelling argument for consideration of the Ross procedure in patients older than age 50 years. In a retrospective analysis from 5 Canadian centers, performing a Ross procedure in appropriately selected patients older than age 50 years was a safe surgical option and associated with excellent valve

From the Division of Cardiovascular and Thoracic Surgery, Duke University Medical Center, Durham, NC.

Disclosures: The authors reported no conflicts of interest.

The Journal policy requires editors and reviewers to disclose conflicts of interest and to decline handling or reviewing manuscripts for which they may have a conflict of interest. The editors and reviewers of this article have no conflicts of interest.

Received for publication Oct 14, 2020; revisions received Oct 14, 2020; accepted for publication Oct 15, 2020; available ahead of print Oct 27, 2020.

Address for reprints: Ryan P. Plichta, MD, Division of Cardiovascular and Thoracic Surgery, Duke University Medical Center, Box 3864, Durham, NC 27710 (E-mail:

Ryan.Plichta@Duke.edu).

J Thorac Cardiovasc Surg 2022;164:846-7

$0022-5223 / \$ 36.00$

Copyright (c) 2020 by The American Association for Thoracic Surgery

https://doi.org/10.1016/j.jtcvs.2020.10.071
Check for updates

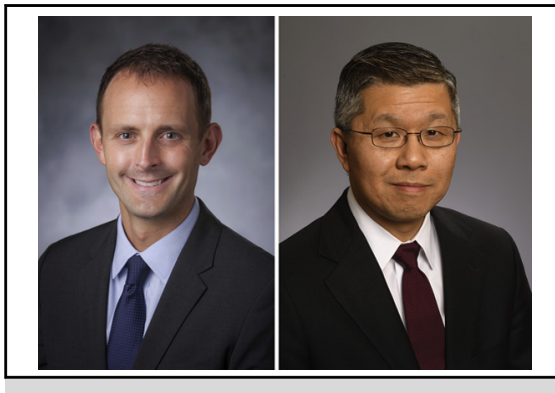

Ryan P. Plichta, MD, and Edward P. Chen, MD

CENTRAL MESSAGE

The Ross procedure, when per-

formed at high-volume centers,

is a safe and durable option for

select patients aged $>50$ years

with aortic valve disease.

durability and survival. The outcomes were excellent and when compared with patients younger than age 50 years who had a Ross procedure, there was no difference in inhospital mortality, perioperative complications, rate of reintervention, or 6-year survival. There were 2 in-hospital mortalities-1 from each group-and the 6-year actuarial survival for both study groups was $>95 \%$.

Patient selection is critical in the decision to offer a Ross procedure and in this report, both the older and younger cohorts had a low median Society of Thoracic Surgeons risk score for mortality $(0.6 \%)$. The older group had more comorbidities, whereas younger patients had more previous interventions, unicuspid valves, and pure aortic regurgitation. The patients were followed with annual echocardiography with $99 \%$ completion and a median follow-up of 2.4 years. The mean gradient at up to 6 years postoperatively was $4 \pm 0.5 \mathrm{~mm} \mathrm{Hg}$. There was no difference in the rate of 